\title{
Design and Simulation of Three Phase Shunt Active Power Filter to Eliminate Harmonics of LED Lighting Loads
}

\begin{abstract}
Non-linear loads are an important fraction of loads in most commercial buildings. Most of these non-linear loads are lighting loads. So a small negative change in their harmonic distortion levels may affect the other loads in the building and the loads that are connected to the same bus. Shunt active power filters inject harmonic current with the same amplitude and opposite phase of the load harmonic current to eliminate the harmonic current flowing into the source. Therefore harmonic and reactive power trouble is solved simultaneously. In this study a three phase shunt active power filter based on synchronous reference frame (SRF) theory is designed and tested with an approximate linear LED model in MATLAB. $A$ three phase current controlled voltage source inverter (VSI) and DC link capacitor is used as an active power filter. Pulses to the inverter are generated by hysteresis band current control (HBCC) technique. The THD, with the shunt active power filter is measured $2.52 \%$ which is within the allowable harmonic limits.
\end{abstract}

Keywords: shunt active power filter, synchronous reference frame, hysteresis band current control, approximate linear led model, compensation.

\section{Introduction}

A nonlinear load is one which draws non-sinusoidal current from the AC utility grid supplying sinusoidal voltage. The non-sinusoidal current or harmonic current injected by nonlinear loads causes the power quality problems of voltage distortions at PCC, overheating, overloading, failure of system components, and resonance in distribution systems [1]. Traditionally LC filters were used to reduce harmonics and capacitors were employed to improve the power factor of the ac loads. However traditional filters have many disadvantages of fixed compensation, large size and resonance problems [2]. So the concern about the increase in harmonic pollution in power networks has put active power filters forward. Modern active power filters are superior in filtering performance, smaller in size and more flexible in application compared to the traditional filters [3].

There are several active power filter topologies developed to meet the IEEE 519 harmonic standards. Parallel active power filter system, hybrid series active power filter system and hybrid parallel active system topologies have been analysed in details for cost and performance comparisons among the other topologies. Results show that parallel active power filter system provides the best harmonic filtering solution [4].

Parallel active power filter system has two main blocks. Out of this one is the harmonic current reference generator and the other one is current controller. Harmonic reference generator block extracts harmonic components of the load current for the three phase voltage source inverter, the main component of the active power filter. There are several topologies to extract these components like synchronous reference frame theory [4-7] and instantaneous reactive power theory [8-10]. Current controller block takes the reference signal and creates switching signals for the inverter. There are different control techniques to create these signals like hysteresis band method [11 and 12].

In this paper to reduce the harmonic pollutions sourced by LED lighting loads, a three phase shunt active power filter based on synchronous reference frame theory is designed and simulated with MATLAB. A three phase current controlled voltage source inverter (VSI) and DC link capacitor is used as an active power filter. Pulses to the inverter are generated by hysteresis band current control

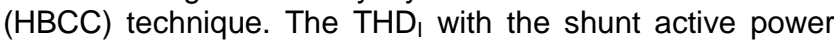
filter is measured $2.52 \%$ which is within the allowable harmonic limits.

\section{Harmonic Reference Current Generator}

Shunt active power filter generates a current equal to the load current harmonics to achieve a utility grid current which is balanced, sinusoidal, and in-phase with the voltage at the PCC. The performance of the shunt active power filter depends on the accuracy of the filter harmonic current reference generation. Therefore the current reference generation of the shunt active power filter is a critical part in the control algorithm in current controlled VSI applications.

Harmonic current reference generation methods can be classified into two groups as frequency domain methods and time domain methods. The frequency domain methods are based on Fourier analysis method of discrete signals such as Discrete Fourier Transform (DFT) and Fast Fourier Transform (FFT). The time domain methods are mainly preferred over frequency domain methods due to their less number of calculations and response speed during transients. In this paper a well-known time domain method, synchronous reference frame (SRF) theory is used.

\subsection{Synchronous Reference Frame Theory}

Figure 1 shows the basic principle of the synchronous reference frame (SRF) controller developed for shunt active power filter system. The measured load currents in ' $a-b-c$ ' frame are transformed to 'ds-qs' frame by the transformation matrix $C$ in (1). Then the transformation matrix $T$ in (2) transforms the current frame to 'de-qe' frame. Here, matrix $T$ needs the phase angle $\theta e$ which is obtained by a phase locked loop (PLL) circuit. PLL circuit generates the AC utility phase angle by 'de-qe' reference frame and PI controller with 3 phase AC utility grid voltages as inputs (Figure 2). In the 'de-qe' frame, the fundamental positive sequence components appear as DC quantities while the fundamental negative sequence current components and the current components at the other frequencies (harmonics) appear as AC quantities with a frequency shift of $50 \mathrm{~Hz}$. Low-pass filters extract the dc quantities, the fundamental positive sequence current components and a high pass implementation (1-LPF) extracts the ac quantities, harmonic components of the load current $\left(I_{\text {deh }}\right)$. After filtering, the harmonic reference signals are transformed to 'ds-qs' frame by the inverse transformation matrix $\mathrm{T}^{-1}$ in (3). Finally the inverse transformation matrix $\mathrm{C}^{-}$ ${ }^{1}$ in (4) obtains the desired 3 phase reference currents, $\mathrm{I}_{\mathrm{fa}}{ }^{*}$, $\mathrm{I}_{\mathrm{fb}}{ }^{*}, \mathrm{I}_{\mathrm{fc}}$ [4 and 13]. 


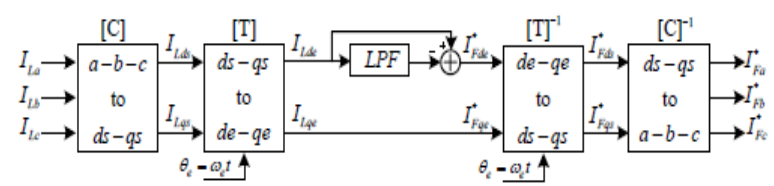

Figure 1. The basic principle of the synchronous reference frame controller

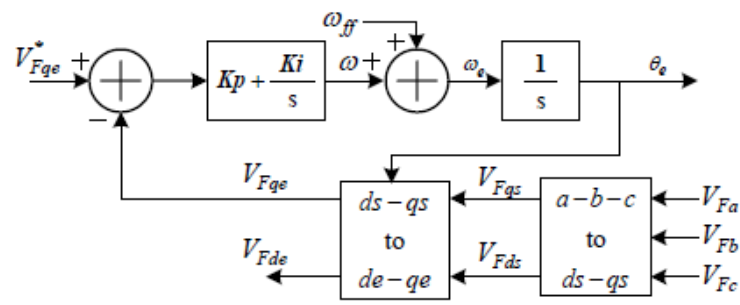

Figure 2. Block diagram of vector PLL system

(1)

$$
\left[\begin{array}{l}
I_{d s} \\
I_{q s}
\end{array}\right]=C\left[\begin{array}{l}
I_{a} \\
I_{b} \\
I_{c}
\end{array}\right]=\left[\begin{array}{lll}
1 & \frac{-1}{2} & \frac{-1}{2} \\
0 & \frac{\sqrt{3}}{2} & \frac{-\sqrt{3}}{2}
\end{array}\right]\left[\begin{array}{c}
I_{a} \\
I_{b} \\
I_{c}
\end{array}\right]
$$

(2)

$$
\left[\begin{array}{c}
I_{d e} \\
I_{q e}
\end{array}\right]=T\left[\begin{array}{l}
I_{d s} \\
I_{q s}
\end{array}\right]=\left[\begin{array}{ll}
\sin \left(\theta_{e}\right) & -\cos \left(\theta_{e}\right) \\
\cos \left(\theta_{e}\right) & \sin \left(\theta_{e}\right)
\end{array}\right]\left[\begin{array}{l}
I_{d s} \\
I_{q s}
\end{array}\right]
$$

(3)

$$
\left[\begin{array}{l}
I_{d s} \\
I_{q s}
\end{array}\right]=T^{-1}\left[\begin{array}{l}
I_{d e h} \\
I_{q e}
\end{array}\right]=\left[\begin{array}{ll}
\sin \left(\theta_{e}\right) & \cos \left(\theta_{e}\right) \\
-\cos \left(\theta_{e}\right) & \sin \left(\theta_{e}\right)
\end{array}\right]\left[\begin{array}{l}
I_{d e h} \\
I_{q e}
\end{array}\right]
$$

$$
\left[\begin{array}{c}
I_{f a}^{*} \\
I_{f b}^{*} \\
I_{f c}^{*}
\end{array}\right]=C^{-1}\left[\begin{array}{c}
I_{d s} \\
I_{q s}
\end{array}\right]=\left[\begin{array}{cc}
1 & 0 \\
\frac{-1}{2} & \frac{\sqrt{3}}{2} \\
\frac{-1}{2} & \frac{-\sqrt{3}}{2}
\end{array}\right]\left[\begin{array}{l}
I_{d s} \\
I_{q s}
\end{array}\right]
$$

\subsection{Bus Voltage Controller}

A dc bus voltage controller generates a fundamental reference current to regulate the dc bus voltage to its reference value and compensate for the inverter losses. A $\mathrm{PI}$ regulator is used as a dc bus voltage controller as shown in Figure 3. The dc bus voltage has dominant as components at $6 w_{1}(300 \mathrm{~Hz})$ as both $5^{\text {th }}$ and $7^{\text {th }}$ harmonics of the filter current $i_{f}$ are transformed into $300 \mathrm{~Hz}$ component on the dc bus side and cause dc bus voltage ripple. Here, $5^{\text {th }}$ harmonic is a negative sequence component and $7^{\text {th }}$ harmonic is positive sequence component. So the dc bus voltage requires filtering.
Otherwise the current reference is created for $6^{\text {th }}$ harmonic component and its multiples [4 and13].

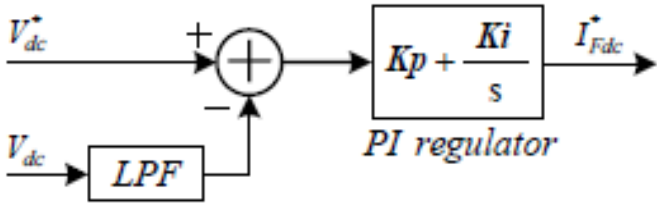

Figure 3. PI regulator as a dc bus voltage controller

The available values of the dc bus voltage are between $650 \mathrm{~V}$ and $750 \mathrm{~V}$ for $380 \mathrm{Vrms}$ line to line voltage level. So the dc bus voltage is selected as $700 \mathrm{~V}$ and the design of PI regulator gains and LPF is made based on this value and other related system parameters in this paper.

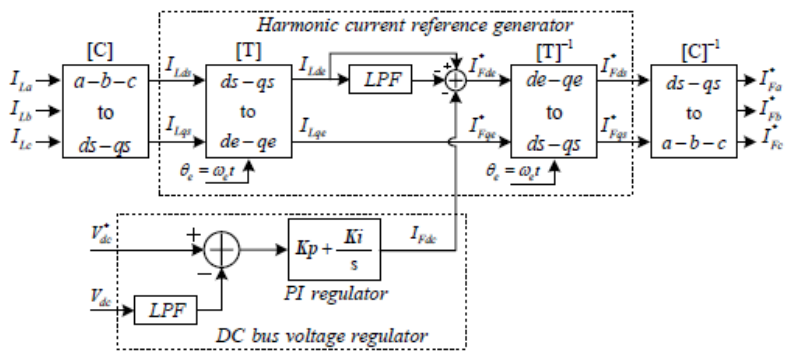

Figure 4. The complete control block diagram of a current reference generator

\section{Current Controller}

The current controller is the part of SAPF where the switching signals to VSI are created. The performance of SAPF is fully determined by the accuracy of switching signals, the current controller. There are different control methods proposed for active power filtering applications. In this paper hysteresis band current control method is utilized for the current controller design.

\subsection{Hysteresis Band Controller}

The hysteresis band current control technique has been typically preferred in active power applications since it provides a stable, fast response with a good accuracy [12].

Figure 5 shows a hysteresis band current controller (HBCC) scheme for a single phase VSI. I $c^{*}$ is the reference line current by the harmonic reference generator and $I c$ is the actual line current of the active power filter.

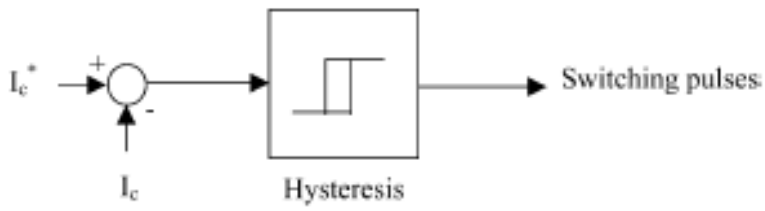

Figure 5. Control block diagram of a single phase HBBC

Switching pulses are generated by a simple formulation. Switching function SA for phase A is determined as follows [12]:

If ica < (ica*- HB) upper switch is OFF and lower switch is ON for leg "a" $(S A=1)$.

If ica $>\left(i c a^{*}+\mathrm{HB}\right)$ upper switch is $\mathrm{ON}$ and lower switch is OFF for leg "a" $(S A=0)$. 
Switching functions SB and SC for phases B and C are defined similarly by the related reference line currents and actual line currents. Figure 6 shows the block diagram of a 3 phase HBCC [14].

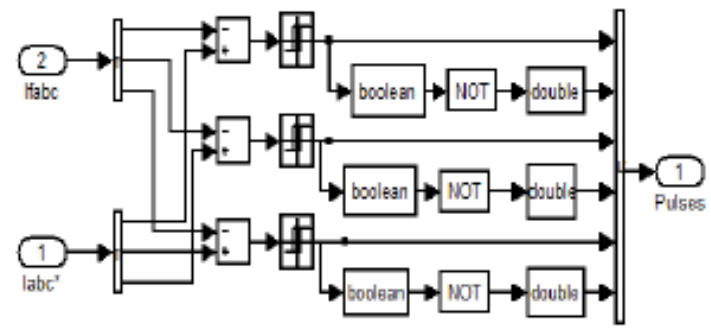

Figure 6. Block diagram of a 3 phase HBCC

In this control method the switching frequency does not remain constant. The changes of the actual active power filter line currents between upper and lower limits of the hysteresis band directly affect the switching frequency. Therefore the capacitor voltage and the line inductance value become significant parameters as they determine the rate of change of the active power filter line currents [12].

\section{Simulation Results and Discussions}

A shunt active power filter is designed and used to compensate the harmonic currents of a three-phase power system. The LED model proposed by Lin R.L. and Chen Y.F. is chosen as the nonlinear load of the system (Figure 7) [13]. All the system parameters are given in Table 1.

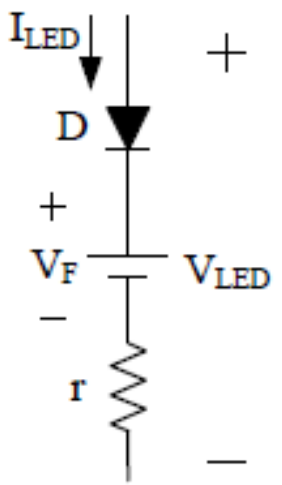

Figure 7. Approximate linear LED model

Table 1. Experimental system parameters

\begin{tabular}{|l|l|}
\hline Parameters & Value \\
\hline Line Voltage & $380 \mathrm{Vrms}$ \\
\hline DC Bus Voltage & $700 \mathrm{~V}$ \\
\hline Line Inductance & $1 \mathrm{mH}$ \\
\hline Filter Inductance & $0.1 \mathrm{mH}$ \\
\hline DC Link Capacitor & $1000 \mathrm{uF}$ \\
\hline$V_{\mathrm{F}}$ & $3.1 \mathrm{~V}$ \\
\hline $\mathrm{r}$ & $13.38 \Omega$ \\
\hline
\end{tabular}

First the behaviour of the system is observed without filtering (Figure 8). Total harmonic distortion (THD) of the system is measured as $44.30 \%$ (Figure 9). Then the system is simulated with the designed shunt active power filter (Figure 10, Figure 11). THD of the new system is measured as $2.52 \%$.

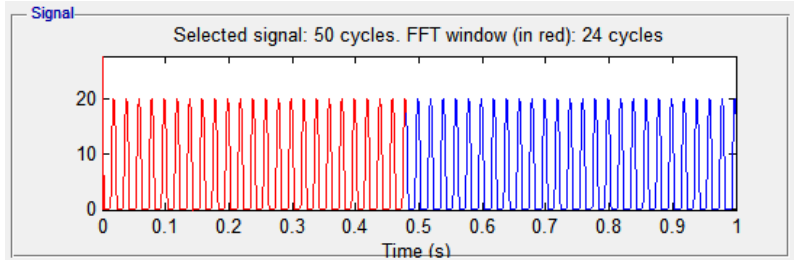

Figure 8. Source current in phase a without filtering

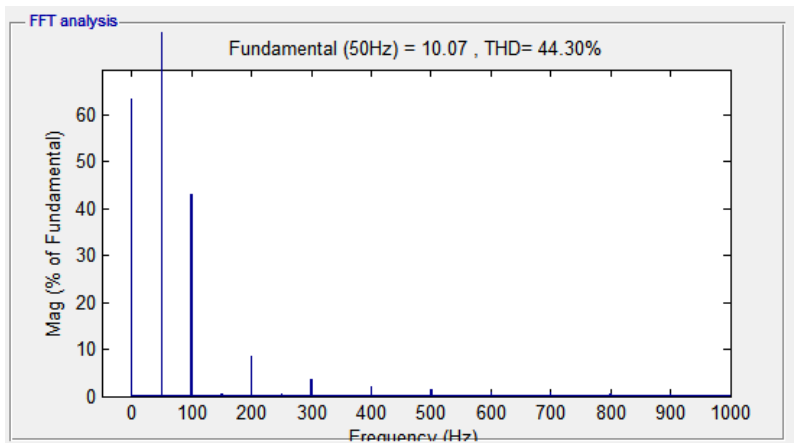

Figure 9. THD spectrum without filtering

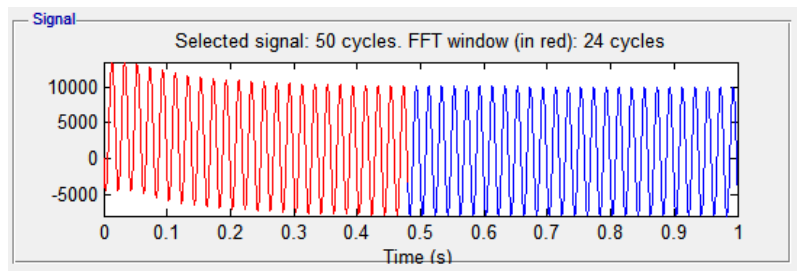

Figure 10. Source current in phase a with filtering

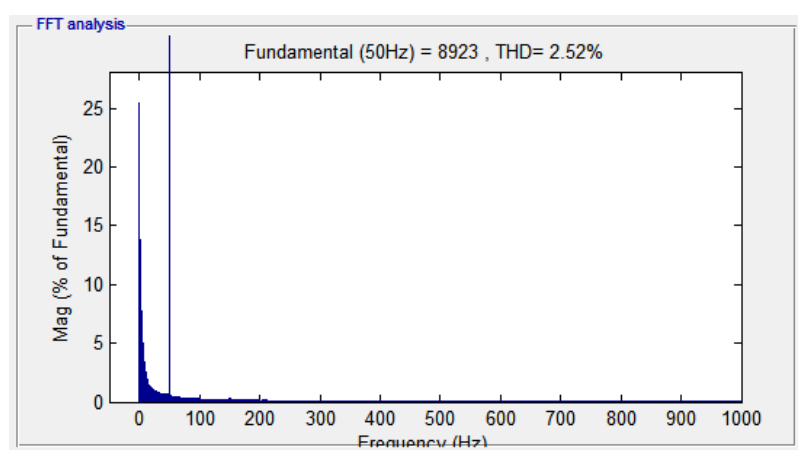

Figure 11. THD spectrum with filtering

\section{Conclusion}

This paper presents a SAPF design to compensate the line current harmonics of a three phase system. A three phase current controlled voltage source inverter (VSI) and DC link capacitor is used as an active power filter. SRF theory is used to generate harmonic current reference generation and HBCC technique is used to generate switching pulses to the inverter. The performance of the SAPF is tested with an approximate linear LED model. Test result shows that the SAPF based on SRF theory is effective with a THD of $2.52 \%$ which is within the allowable harmonic limits of IEEE standards.

Since Led light sources are used with drivers including electronic circuits, high THD is always a problem to solve for a better electricity network. Using DALI or classic driving methods for LED lighting, THD filtering is a necessity for network stability and reliability. Therefore integrating the shunt active power filter to large LED lighting loads (e.g. factories, govermental offices) shall provide a better network stability. 


\section{REFERENCES}

[1] Dugan R. C., McGranaghan M. F.: Electrical power

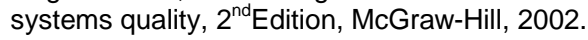

[2] Singh B., Al-Haddad K., Chandra A.: A Review of active filters for power quality improvement, IEEE Transactions on Industrial Electronics, 46 (1999), No. 5, 960-971.

[3] Akagi $\mathrm{H} .:$ Active harmonic filters, Proceedings of the IEEE, 93(2005), No.12, 2128-2141.

[4] Bhattacharya S., Frank T.M., Divan D. M., Banerjee B.: Active filter system implementation, IEEE Industry Applications Magazine, September/October 1998, 4763.

[5] Mendalek N., Al-Haddad K.: Modelling and nonlinear control of shunt active power filter in the synchronous reference frame, Harmonics and Quality of Power 2000, Proceedings of the Ninth International Conference, 1 (2000), 30-35.

[6] da Silva S.A.O., Neto A.F., Cervantes S.G.S., Goedtel A., Nascimento C.F.: Synchronous reference frame based controllers applied to shunt active power filters in three-phase four-wire systems, Industrial Technology (ICIT), 2010 IEEE International Conference, 832-837.

[7] Pridaaa J.S., Tamizharasi P., Baskaran J.: Implementation of synchronous reference frame strategy based shunt active filter, Electronics Computer Technology (ICECT), 2011 3rd International Conference, 2 (2011), 240-244.

[8] Akagi $\mathrm{H}$.: Trends in active power line conditioners, IEEE Transactions on Power Electronics, 9 (1994), No.3, 263-268.

[9] Peng F.Z., Lai J.S.: Generalized instantaneous reactive power theory for three-phase power systems, IEEE Transactions on Instrumentation and Measurement, 45 (1996), No. 1, 293-297.

[10] Salmeron P., Herrera R.S., Vazquez J.R.: A new approach for three-phase loads compensation based on the instantaneous reactive power theory, Electric Power Systems Research, 78 (2008), 605-617.

[11] Zeng J., Yu C., Qi Q., Yan Z., Ni Y., Zhang B.L., Chen S., Wu F.F.: A novel hysteresis current control for active power filter with constant frequency, Electric Power Systems Research, 68 (2004), 75-82.

[12] Kale M., Özdemir E.: An adaptive hysteresis band current controller for shunt active power filter, Electric Power Systems Research, 73 (2005), 113-119.

[13] Özkaya H.: Parallel active filter design, Control, and Implementation, Master Thesis, Middle East Technical University, 2007.

[14] Rejil C., Anzari M., Arun Kumar R.: Design and simulation of three phase shunt active power filter using SRF theory, Advance in Electronic and Electric Engineering, 3 (2013), No. 6, 651-660.

[15] Lin R.L., Chen Y.F.: Equivalent circuit model of lightemitting-diode for system analyses of lighting drivers, IEEE Industry Applications Society Annual Meeting, 2009, ISBN 978-1-4244-3476-3.

\footnotetext{
Authors:

Research Assistant Ceyda Aksoy Tırmıkçı, Sakarya University, Eng. Faculty, Electrical and Electronics Eng. Dept., Esentepe Campus, 54187, Sakarya, Turkey, e-mail: caksoy@sakarya.edu.tr

Asst. Prof. Dr. Cenk Yavuz, Sakarya University, Eng. Faculty, Electrical and Electronics Eng. Dept., Esentepe Campus, 54187, Sakarya, Turkey, e-mail:

cyavuz@sakarya.edu.tr
} 